Subcarb. of soda, 1 drachm;

Camphor mixture, 5 ounces;

Tinct. of ipecac., 1 drachm;

Comp. spirit of ammonia, $1 \mathrm{drachm}$. fourth part every six hours.

Alum, 1 drachm;

Co. infus. of roses, $1 \frac{1}{2}$ ounces; gargle.

Tinct. of myrrh, $\frac{1}{2}$ ounce. Make

His diet to consist of milk principally, va. ried with an occasional light pudding, or arrow-root, sago, and his ordinary drink, toast and water, flavoured with a tablespoonful of brandy to each tumbler.

7. Salivation increased; otherwise the same as yesterday. Continue medicines; a dose of castor oil to relieve the bowels.

8. His features are now so swollen that he can scarcely be recognised by his friends; the salivation is profuse; his breath very offensive; the bowels and pulse regular; complains of thirst; perspires freely in bed. Ordered warm fomentations to the head and face. Continue mixture. His tongue is so much enlarged that he cannot use the gargle.

Borate of soda, two drachms, to be mixed with honey and applied to the mouth.

This treatment was pursued, with progressive improvement, until the $16 \mathrm{th}$, when the swelling of the head and face, and all the more prominent symptoms subsided. Previous to his application to me he had been afficted, for years, with dyspepsia of a severe character, accompanied with painful vomiting every morning after quitting his bed. He had sought the advice of various practitioners without obtaining permanent relief, and naturally felt reluctant to confide himself to my care, believing his case to be hopeless, and admitting of slight palliation only. I may here state that $I$ availed myself of the opportunity so unexpectedly afforded me, to combat the primary affection, and that, by the administration of appropriate remedies, a cure was effected, probably accelerated by the salivation; he is now in better health than he has been for years.

\section{INJECTION OF DEAD BODIES.}

To the Editor of The LANCET.

SrR :-I beg leave to send for insertion, in your widely-circulating periodical, an outline of an instrument which $I$ have invented for the purpose of facilitating the injection of the dead subject, through a medio-vertical section of the sternum. By the employment of the usual means considerable difficulty is met with in separating the segments of the bone far enough to admit of the injecting pipe being secured in the vessel, with the certainty of ensuring a free injection, without extravasion of the fluid into the thorax. This difficulty is completely obviated by the instrument. On IV onday last I had an opportumity of trying its power on a fine muscular male subject, in the dissecting-room of the Westminster School of Medicine, through the kindness of one of the lecturers, Mr. Savage, to whom, indeed, Iam indebted for many valuable suggestions, whilst manufacturing his instruments for the dissecting-room.

The two plates, closely approximated, were inserted into the fissure left by the

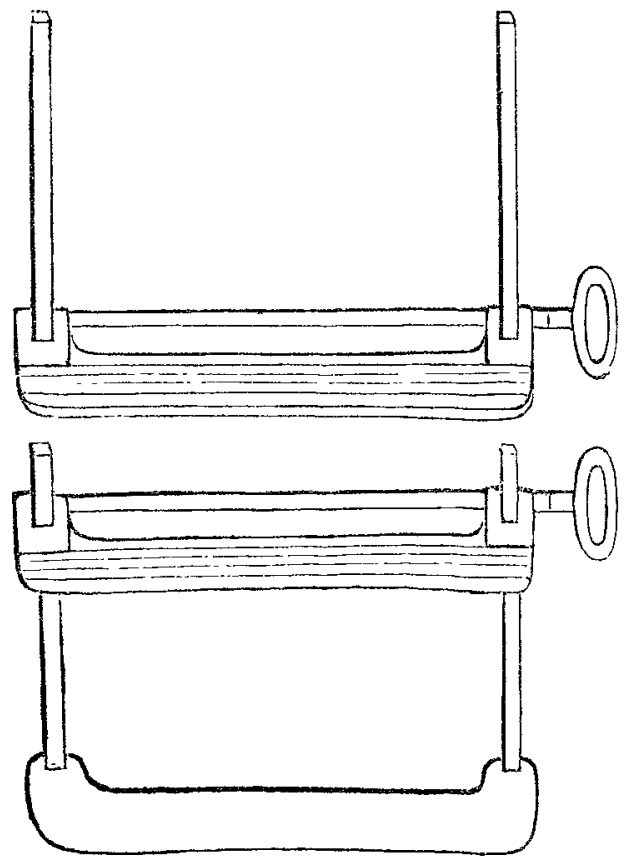

saw; a few turns of the handle sufficed to dilate it to the extent of six inches, withont the slightest disturbance of the thoracic viscera. Begging the favour of an early insertion I remain, Sir, your obedient servant,

35 Charles-street, Middlesex Hospital, Nov. 12, 1838.

\section{MONSTROUS FEMALE FETUS.}

\section{To the Editor of THE LANCET.}

SIR:-Should you deem the drawings I have made and forwarded to you, of a child which was born on the 23rd instant, worthy of insertion in the pages of your Journal, I freely present them for your adoption.

I remember, during my articleship with Mr. Higginbottom, of Nottingham, a simi. lar production being shown me; but the malformation of the spine was not carried to near the extent, nor had the child arrived at half the age of the one now shown in the engraving. The preparation is now in the possession of Dr. Taylor, St. Paul'ssquare. I have the honour to be, Sir, your very obedient servant,

W. Andrew, Surgeon, \&c,

Liverpool, Oet. $31,1838$. 
The front view, or Fig. 1 , of this female monster, represents the muscles and bones of the lower maxilla, resting without much cellular substance, or flesh, upon the sternum below the fourth rib. The ribs below are in a perfect state; but the belly and circumference of the abdomen are large to an extensive degree.

Letter A shows the umbilical cord, which is perfectly healthy and natural, and the foetal circulation continued through it nearly to the time of parturition. The arms and legs are of equal length, though the wavering position the subject was held in by my attendant, makes a leg and an arm appear shorter in this view than is necessary. It may, however, be observed, that this representation is taken in a sitting position, and the second view shows the back in a standing one.

Throngh the mouth, which is partially open, protrudes the tongue; the eyes (now considerably dimmed by the action of the spirit) were, at the time of its birth, blue. The superciliary ridges, marked $\mathbf{B} B$, in the front view, and $c c$, in the back view, show the limits of ossification: The whole of the back part of the head, to the utmost verge of the occiput, was wanting, and the deficiency of bone was supplied by the " dura mater" and "pia mater" in the form of a bag, which hung suspended over the back. as far as the last dor'sal vertebre.

Letter $A$, in the second, or back figure, shows the cavity of the head, after it was inadvertently deprived of its brain, and bag-like appendages. There is no chance of demonstrating its contents further, it being a solid mass of jumbled-up blood and bone: the most remarkable points connected with this monster are the absence of the cervical vertebræe, and the adherence of the head to the dorsal vertebræ.

My inquiries of the woman who gave birth to the child were fruitless; nothing could be adducerl further than that she had many times received ill-treatment from her drunken hushand, and that the defects of the birth was but a judgment on the man whose partial image is presented in the engraving.
Fig. 1.

(Front view.)

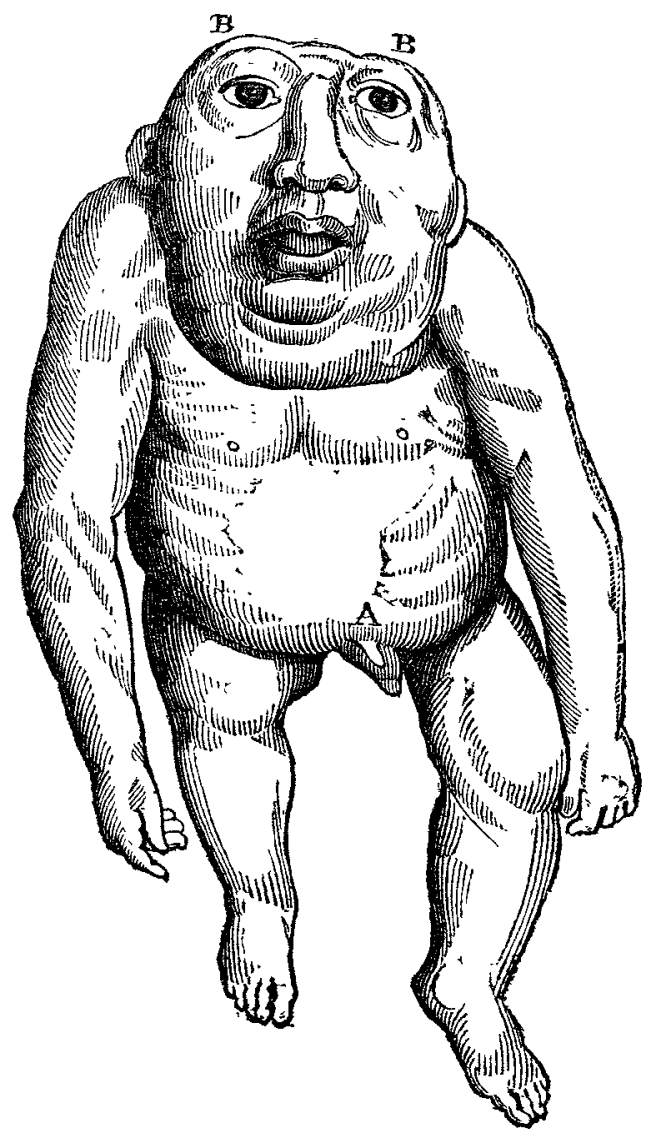

Fig. 2.

(Back view.)

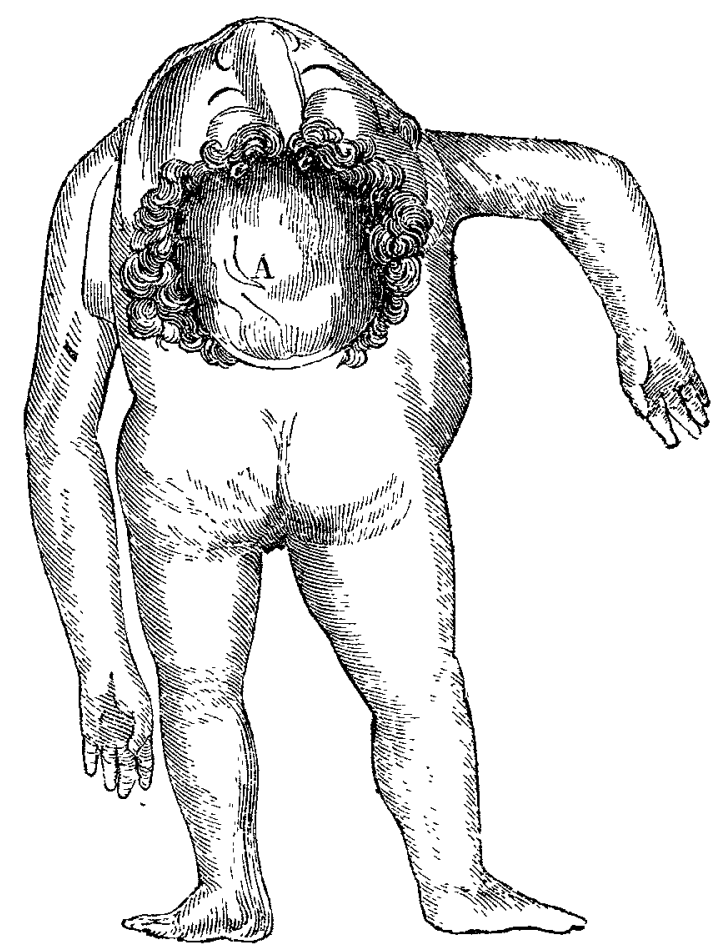

